\title{
When nutrition interacts with osteoblast function: molecular mechanisms of polyphenols
}

\author{
Anna Trzeciakiewicz, Véronique Habauzit and Marie-Noëlle Horcajada* \\ INRA Clermont-Ferrand/Theix, Human Nutrition Unit UMR1019, St Genès Champanelle F-63122, France
}

\begin{abstract}
Recent research has provided insights into dietary components that may optimise bone health and stimulate bone formation. Fruit and vegetable intake, as well as grains and other plant-derived food, have been linked to decreased risk of major chronic diseases including osteoporosis. This effect has been partially attributed to the polyphenols found in these foods. Thus, it has been suggested that these compounds may provide desirable bone health benefits through an action on bone cell metabolism. The present review will focus on how some polyphenols can modulate osteoblast function and reports which cellular signalling pathways are potentially implicated. However, to date, despite numerous investigations, few studies have provided clear evidence that phenolic compounds can act on osteoblasts. Polyphenols cited in the present review seem to be able to modulate the expression of transcription factors such as runt-related transcription factor-2 (Runx2) and Osterix, NF-кB and activator protein-1 (AP-1). It appears that polyphenols may act on cellular signalling such as mitogen-activated protein kinase (MAPK), bone morphogenetic protein (BMP), oestrogen receptor and osteoprotegerin/receptor activator of NF-кB ligand (OPG/RANKL) and thus may affect osteoblast functions. However, it is also important to take in account the possible interaction of these compounds on osteoclast metabolism to better understand the positive correlation reported between the consumption of fruit and vegetables and bone mass.
\end{abstract}

Bone metabolism: Osteoblasts: Polyphenols: Signalling

\section{Introduction}

The vertebrate skeleton is composed of two specialised tissues, cartilage and bone. Bone is essential for human beings as its main role is to provide structural support for the body, protect the organs, contribute to haematopoiesis and store minerals ${ }^{(1)}$. Three distinctly different cell types can be found within bone: the osteoblasts responsible for the synthesis and mineralisation of bone, the osteoclasts implicated in bone tissue resorption and the osteocytes which are the most abundant cells present in the adult skeleton $^{(2)}$. The integrity of the skeleton requires a dynamic balance between bone formation and bone resorption (Fig. 1). If a dysfunction occurs in these two processes, pathologies, such as osteoporosis, can develop.

Osteoporosis is the most common of all bone diseases in adults, especially in old age. This bone disorder is characterised by an increased risk of fracture due to a reduction in both bone quantity and quality. The concerns about the medical, social and financial impacts of this disease are increasing. Therefore it is important to develop strategies and recommendations not only for the treatment but also for the prevention of osteoporosis. Most of the current pharmacological approaches focus on inhibiting bone resorption in those who already have the disease or in those who are at risk of developing the disease ${ }^{(3,4)}$. On the contrary, recent research has given insight into dietary components that may optimise bone mass and stimulate bone formation ${ }^{(5)}$. Concerning dietary matter, several nutritional factors are implicated in ensuring optimal bone health. Numerous studies have reported the essentiality of $\mathrm{Ca}$ and vitamin $\mathrm{D}$ for bone health ${ }^{(6-8)}$. However, in many countries in Europe and North America, where the dietary intake of $\mathrm{Ca}$ is adequate for most individuals compared with recommended daily allowances, very high rates of

Abbreviations: AKT, protein kinase B; ALP, alkaline phosphatase; AP-1, activator protein-1; BMP, bone morphogenetic protein; EGCG, (-)-epigallocatechin-3-gallate; ERK, extracellular signal-regulated kinase; hFOB, fetal human osteoblastic cell line; JNK, c-Jun N-terminal kinase; MAPK, mitogen-activated protein kinase; MC3T3-E1, murine osteoblastic cells; MG-63, human osteosarcoma cell line; OPG, osteoprotegerin; PI3K, phosphoinositide 3-kinase; RANK, receptor activator of NF-кB; RANKL, RANK ligand; Runx2, runt-related transcription factor-2; SaOS-2, sarcoma osteogenic cells; SMAD, mothers against decapentaplegic homologue.

* Corresponding author: Dr M. N. Horcajada, fax +33 4736246 38, email horcajad@clermont.inra.fr 


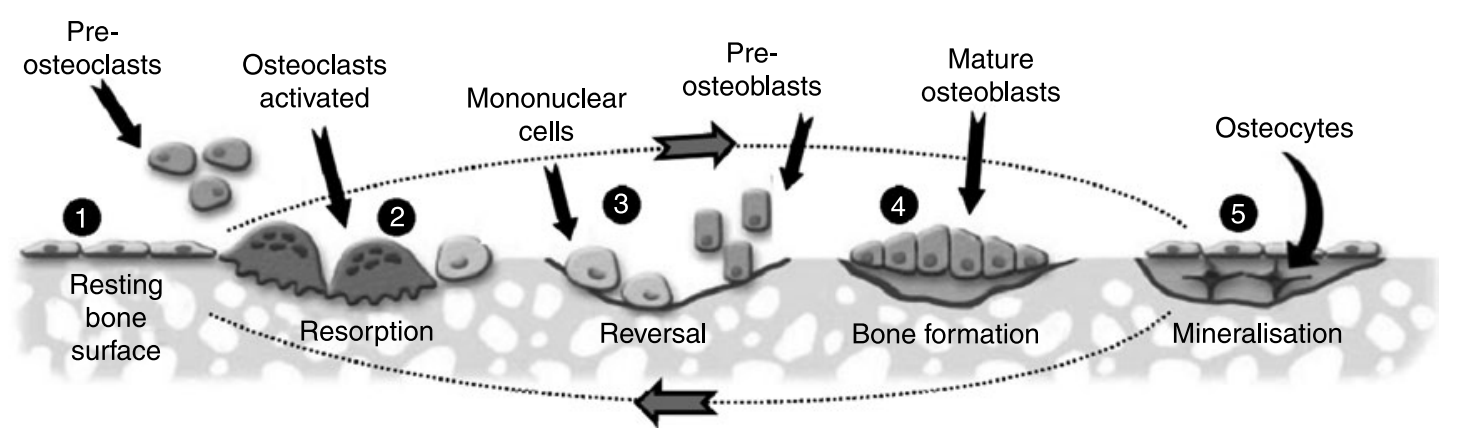

Fig. 1. Bone remodelling cycle (adapted from University of Michigan ${ }^{(122)}$ ). (1), Quiescence; (2), osteoclastic resorption; (3), osteoblast recruitment; (4), osteoblastic formation; (5), bone mineralisation.

osteoporosis are nevertheless observed. These observations suggest that other nutrients and dietary factors may influence bone and mineral homeostasis and may be important for long-term bone health. Specifically, it is now well recognised that the human diet contains, in addition to essential macro- and micronutrients, a complex array of naturally occurring bioactive molecules, namely phytonutrients that may provide long-term health benefits. Indeed, these compounds have been linked to reductions in the risk of major chronic diseases including osteoporosis.

As previously described by Habauzit \& $\operatorname{Horcajada}^{(9)}$, phytonutrients and especially polyphenols can act on both osteoblasts and osteoclasts to modulate bone metabolism. The aim of the present paper is to review how they can modulate osteoblastic function responsible for bone formation and to report the cellular mechanisms involved.

\section{Osteoblast metabolism}

Bone formation is a tightly regulated process characterised by a sequence of events starting with the commitment of osteoprogenitor cells from mesenchymal cells, their differentiation into immature pre-osteoblasts and then into mature functional osteoblasts ${ }^{(10)}$.

\section{Characteristics of osteoblasts and their lineage}

Morphologically, osteoblasts have a cuboidal shape and they form a dense monolayer of cells at the bone surface. Functionally, osteoblasts are the specialised cells within bone that produce extracellular matrix and also regulate mineralisation ${ }^{(2)}$. More precisely, bone tissue consists of hydroxyapatite crystals and various extracellular matrix proteins (i.e. type I collagen, osteocalcin, osteonectin, osteopontin, bone sialoprotein and proteoglycans) secreted and deposited by mature osteoblasts ${ }^{(11)}$.

Osteoblasts are derived from precursors originating in the bone marrow. These precursors are multipotent mesenchymal stem cells that can differentiate into several kinds of tissue-specific cells such as osteoblasts, myoblasts, adipocytes and chondrocytes. Each differentiation pathway can be specifically regulated by transcription factors such as runt-related transcription factor-2 (Runx2)/Osterix, MyoD family, PPAR $\gamma$ and SOX5/6/7, respectively ${ }^{(12)}$.

\section{Regulation of osteoblastogenesis}

In the process of osteoblastogenesis, different stages are involved including proliferation, extracellular matrix synthesis, maturation and mineralisation. Each stage is regulated by the coordinated expression of major transcription factors ${ }^{(10)}$. The most important transcription factors controlling bone formation are Runx2, Osterix, $\beta$-catenin, activating transcription factor-4, activator protein-1 (AP-1) and CCAAT/enhancer binding proteins (C/EBP). Other transcription factors belonging to homeobox proteins (Msx and Dlx proteins) or to helix-loop-helix proteins (Id and Twist) may play a role in osteoblast development ${ }^{(10)}$. Furthermore, the expression of all these transcription factors is known to be modulated by several hormones (parathyroid hormone, oestrogens, glucocorticoids, 1,25dihydroxyvitamin $\mathrm{D})^{(13)}$ or growth factors (bone morphogenetic protein (BMP), transforming growth factor- $\beta$, insulin-like growth factor-1, fibroblast growth factor-2) ${ }^{(14)}$.

Osteoblast differentiation is stimulated by some hormones and local factors which act on signalling pathways in cells within the osteoprogenitor lineage ${ }^{(15)}$. Various pathways such as BMP, transforming growth factor- $\beta$, insulin-like growth factor, fibroblast growth factor, Hedgehog, WNT (wingless-type MMTV integration site family) and mitogen-activated protein kinase (MAPK) have been implicated ${ }^{(15-19)}$ (Fig. 2). Many markers are available and currently used to study the influence of several factors on osteoblast developmental stages or functions. Indeed, alkaline phosphatase (ALP) collagen type I, osteopontin and bone sialoprotein are early markers of the osteoblast phenotype while osteocalcin plays a role in mineralisation ${ }^{(20)}$ (Fig. 3). Cytokines and/or growth factors produced by osteoblasts and other cells have an effect on differentiation and the maturation process through binding to the proteins of bone extracellular matrix. Mature osteoblasts surrounded by bone matrix become osteocytes. They probably function as mechanosensors which regulate the bone response to mechanical stimuli ${ }^{(21)}$. Activated osteocytes produce signalling molecules such as NO, which could stimulate the activity of osteoblasts and osteoclasts. Intercellular signalling is essential for bone adaptation ${ }^{(22)}$. Thus, bone cells cooperate together and regulate their own functions. 


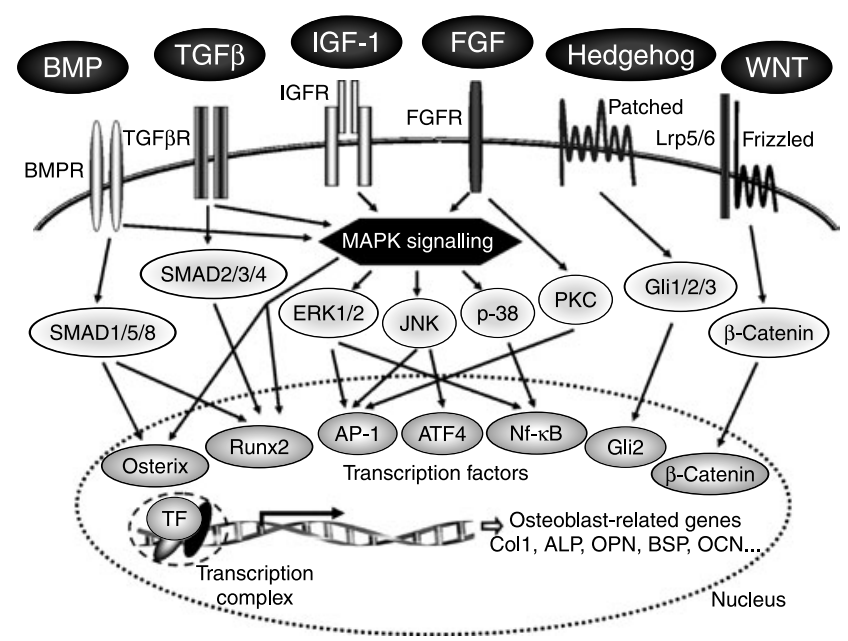

Fig. 2. Signal-transduction pathways implicated in regulation of osteoblast functions. BMP, bone morphogenetic protein; TGF $\beta$, transforming growth factor- $\beta$; IGF-1, insulin-like growth factor-1; FGF, fibroblast growth factor; WNT, wingless-type MMTV integration site family; BMPR, bone morphogenetic protein receptor; TGF $\beta R$, transforming growth factor- $\beta$ receptor; IGFR, insulin-like growth factor receptor; FGFR, fibroblast growth factor receptor; Lrp5/6, LDL-related protein 5/6; SMAD, mothers against decapentaplegic homologue; MAPK, mitogen-activated protein kinase; ERK, extracellular signal-regulated kinase; JNK, C-Jun $\mathrm{N}$-terminal kinase; PKC, protein kinase C; Gli, glioma-associated oncogene; Runx2, runt-related transcription factor-2; AP-1, activator protein-1; ATF4, activating transcription factor-4; TF, transcription factors; Col1, type 1 collagen; ALP, alkaline phosphatase; OPN, osteopontin; BSP, bone sialoprotein; OCN, osteocalcin.

Osteoblasts regulate osteoclastogenesis and osteoblasts play a direct and essential role in the regulation of osteoclast function within the bone microenvironment. Osteoclasts derive from haematopoietic progenitors (monocyte/macrophage lineage) in the bone marrow and they are formed by the fusion of precursor cells ${ }^{(23)}$. They are responsible for bone resorption and therefore for normal skeletal development (growth and modelling). Macrophage colony-stimulated factor produced by osteoblasts/stromal cells is crucial for osteoclast formation and development ${ }^{(24-26)}$. It has been shown that the osteoprotegerin

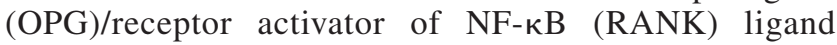

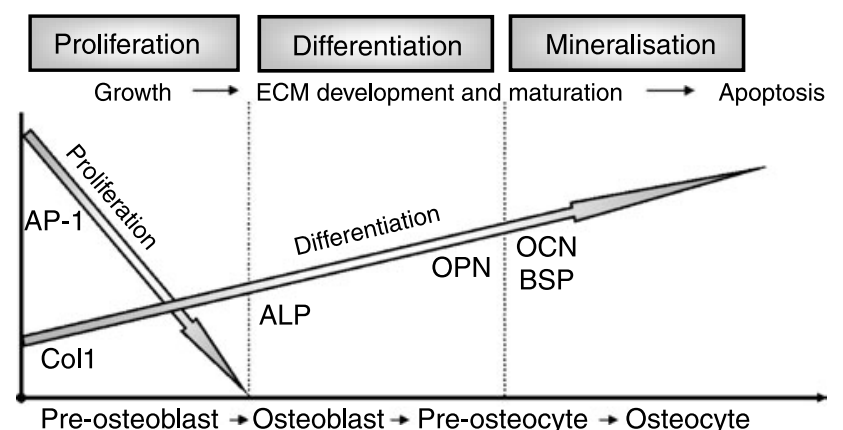

Fig. 3. Main factors produced by osteoblasts and used as markers of different developmental stages (adapted from Stein \& Lian ${ }^{(20)}$ ). ECM, extracellular matrix; AP-1, activator protein-1; Col1, type 1 collagen; ALP, alkaline phosphatase; OPN, osteopontin; OCN, osteocalcin; $\mathrm{BSP}$, bone sialoprotein.
(RANKL)/RANK system plays a role in osteoclastogenesis as the dominant and final mediator of this process.

There are many factors that can influence osteoblastogenesis and/or osteoclastogenesis. It is very important to maintain the balance between these cellular processes which correspond with bone formation and bone resorption. An imbalance between these processes could lead to a decrease in bone mineral density and thus to an increase in the risk of osteoporosis during ageing ${ }^{(27)}$.

\section{Cellular models for bone formation}

The molecular events that regulate osteoblastic differentiation and function are frequently studied using in vitro cellular models. In order to explore the impact of pharmacological agents or dietary molecules, various osteogenic cell-culture systems can be used: immortal cell lines (for example, murine osteoblastic cells (MC3T3-E1) or fetal human osteoblastic cell line (hFOB)) or genetically atypical cell lines derived from tumours (for example, sarcoma osteogenic cells (SaOS-2) or human osteosarcoma cell line (MG-63)). However, tumour origins and genetic alterations associated with the prolonged culture of cell lines can raise questions about the extent to which they match the normal in vivo physiology. That is why in vitro model systems using primary osteoblast precursor cells derived from either the developing calvaria of neonatal rodents or from the bone marrow (murine bone marrow mesenchymal stem cells, human bone marrow-derived mesenchymal stem cells) should be promoted.

\section{Polyphenols: structure, metabolism and cellular bioactivities}

\section{Structure}

Phytochemicals are a large group of plant-derived nonnutritive chemical compounds divided into several classes: phenolics (polyphenols), carotenoids, alkaloids, sterols, terpenes and fibre. Phytochemicals produced by plants are used to protect themselves but recent research demonstrates that certain molecules may protect humans against some pathologies such as cancer, cardiovascular diseases and osteoporosis $^{(28)}$.

Polyphenols can be divided into different groups depending on the number of phenol rings they contain and on the structural elements bound to these rings. Considering this, polyphenols have been classified as phenolic acids, flavonoids, stilbenes, tannins, coumarins and lignans. Moreover, among flavonoids, six subclasses exist and share a common structure of two aromatic rings (A and B) bound together by three carbon atoms that form an oxygenated heterocycle (ring C). These are flavones, flavonols, flavanones, isoflavones, flavanols (catechins and proanthocyanidins) and anthocyanidins ${ }^{(29)}$.

\section{Metabolism of polyphenols}

Knowledge on phenolic metabolites generated in an organism is useful to choose the appropriate molecule for in vitro studies. Biological activities of polyphenols are 
often examined in cell lines usually treated with aglycones or polyphenol-rich extracts (glycoside forms) at concentrations which elicit an appropriate response ${ }^{(30)}$. The compounds abundant in plants are not exactly the same as those found in plasma. Neither aglycones (except for green tea catechins) nor forms found in the diet reach the blood and tissue. The compounds, after consumption, are metabolised by the organism and/or microflora enzymes to conjugates of glucuronate or sulfate (with or without methylation across the catechol functional group) during absorption to the bloodstream and/or eventually eliminated $^{(31)}$. The circulating forms may possess different biological properties within cells and tissues compared with polyphenol aglycones. Moreover, the maximum plasma concentration of polyphenols from foods is in the range of $0 \cdot 1-10 \mu \mathrm{M}$. As far as possible, conjugates of molecules should be used for in vitro studies in the physiological concentration $^{(32)}$ even if they are poorly or not absorbed by cells $^{(33)}$. Unfortunately, many metabolites are not commercialised due to problems of isolation and synthesis and it is difficult to obtain them for in vitro experiments ${ }^{(32)}$. However, some cells (in organisms) could potentially deconjugate the circulating molecules through the activity of enzymes such as $\beta$-glucuronidase and be present in cells in the aglycone form ${ }^{(34)}$. Hence, this enzyme in human tissues could play a role in the turnover of flavonoids (conjugated/non-conjugated forms). It has also been shown that cells in culture are able to take up aglycone forms of flavonoids such as diosmetin, hesperetin and naringenin and conjugate them ${ }^{(33)}$. Treatments of cells with conjugated forms are the most representative method to investigate the molecular mechanism of polyphenols. However, at the present time, there are no reported studies that have used conjugated forms in osteoblastic cells. In the present review, concerning nutrition we focused on studies of molecules at physiological doses (up to $10 \mu \mathrm{M}$ ) corresponding to the concentration of polyphenols found in plasma after polyphenol-containing food consumption.

\section{Cellular bioactivities of polyphenols}

The chemical structure of compounds is related to their biological activity and thus activation of different signalling pathways could be involved ${ }^{(35)}$ in their mode of action.

Flavonoids and more recently their metabolites (sulfates, glucuronides, $O$-methylated forms) have been shown to act on cells, independently of their antioxidant capacity $^{(32,36-38)}$. They may interact with specific proteins involved in intracellular signalling pathways ${ }^{(39)}$. They can selectively act on protein kinase and lipid kinase signalling cascades such as MAPK, protein kinase $\mathrm{C}$, protein kinase B (PKB/AKT) (serine/threonine kinase), tyrosine kinases and phosphoinositide 3-kinase (PI3K) (for a review, see Williams et al. $\left.{ }^{(40)}\right)$. The regulation can occur at transcriptional and/or post-translational levels by the modulation of gene expression and/or phosphorylation of target proteins, respectively. The positive or negative effects of flavonoids depend on both cell type and metabolic disorder. For example, genistein (isoflavone) can inhibit protein tyrosine kinases and thus cause cell cycle arrest and apoptosis in leukaemic cells ${ }^{(41)}$ whereas it can stimulate osteoblast differentiation ${ }^{(42,43)}$. The flavonoid-stimulated signalling pathways are more precisely described by Williams et al. ${ }^{(40)}$ and Orzechowski et al. ${ }^{(44)}$.

Flavonoids also have an impact at the transcriptional level. They may affect the expression of NF- $\mathrm{B}$ and AP-1 composed of c-jun/c-fos complexes which are implicated in the MAPK pathway. Indeed, it has been shown that green tea polyphenols such as (-)-epigallocatechin-3-gallate (EGCG) can modulate phosphorylation of extracellular signal-regulated kinase (ERK) 1/2, c-Jun N-terminal kinase (JNK) and p38 MAP kinase in normal human epidermal keratinocytes $^{(45)}$, which shows that this polyphenol can affect the MAPK signalling pathway ${ }^{(46)}$. In the same way, resveratrol (trans-3,4',5-trihydroxystilbene), a natural stilbene present abundantly in grape skins and red wine, has cardioprotective effects ${ }^{(47)}$, cancer-preventive properties ${ }^{(48)}$ and an impact on bone metabolism ${ }^{(49)}$. It has been shown that resveratrol could act through ERK1/2 and p38 MAPK signalling ${ }^{(50)}$, similar to flavonoids.

Beside these indirect molecular effects, it is possible that the positive health effects of polyphenols occur through their direct action on response elements in the regulatory regions of target genes ${ }^{(44)}$. Some phenolic compounds can bind to specific cytoplasmic receptors which can play a role as DNA binding transcription factors to regulate target gene expression. This mechanism is well known for glucocorticoids $^{(51)}$ and oestrogens ${ }^{(52)}$ which bind to glucocorticoid and oestrogen receptors, respectively. These complexes enter the nucleus to stimulate the expression of glucocorticoid- or oestrogen-related genes. Some plant compounds, so-called phyto-oestrogens, can interact with oestrogen receptors. This is the case for soyabean isoflavones (mainly genistein, daidzein and glycitein) as well as flavonoids such as luteolin and naringenin that exhibit oestrogenic properties ${ }^{(53)}$. These phytochemicals play a role as partial agonists and/or antagonists of oestrogen receptors and can modulate the oestrogen-dependent pathway ${ }^{(54)}$

\section{Mechanisms of polyphenols in osteoblastic cells}

Cellular processes are complex and many components interact together. Cell signalling can be activated by interaction of compounds with a receptor on the cell surface and/or by interaction with extracellular proteins ${ }^{(32)}$. To understand cell signalling during development it is better to study whole signalling networks, not just their individual elements ${ }^{(55)}$. Moreover, gene expression depends on cellular development and time of molecule exposure. Unfortunately, most experiments reported to date were performed to study individual elements of signalling pathways at precise time-points.

Studies of modulation of cell functions by polyphenols have been performed in different in vitro models such as cancer cells ${ }^{(56-58)}$, epithelial cells ${ }^{(59,60)}$ or skeletal cells. However, little is known regarding osteoblastic cells. As previously reviewed by Habauzit \& Horcajada ${ }^{(9)}$, phenolic compounds can act on bone metabolism. Osteoblast proliferation, differentiation and mineralisation as well as osteoclast functions may be modulated by polyphenols. But how do cells read and translate the signal induced by polyphenols? The present review will now report what is 
known about molecular mechanisms activated when polyphenols (listed in Fig. 4) interact with osteoblasts, leading to a modulation of their function.

\section{Effect of polyphenols on transcription factors}

It is known that macro- and micronutrients may enter cells and then interact with transcription factors which are known to influence target gene expression ${ }^{(61)}$. Considering the field of bone metabolism and more specifically osteoblasts, it has been reported that some polyphenols such as EGCG, resveratrol and icariin can modulate some transcription factors which in turn can activate osteoblast-related genes (Table 1).

Runt-related transcription factor-2 and Osterix. There are many transcription factors implicated in the regulation of osteoblast functions $^{(10)}$. Among them, Runx2 and Osterix transcription factors are essential molecules to induce osteoblastic differentiation and can activate some genes implicated in this process ${ }^{(19,62,63)}$.

BMP signalling, well known to be implicated in osteoblast differentiation, may up-regulate expression of Runx2. This factor is known to activate the transcription of various osteoblast-related genes (leading to osteoblast differentiation $)^{(16,64)}$. Another important transcription factor involved in modulating osteoblast function is Osterix, mediated by multiple signalling pathways ${ }^{(63)}$. Indeed, in an animal experiment, expression of osteoblast markers such as osteonectin, osteopontin, osteocalcin, and bone sialoprotein was decreased in Osterix-null mutant mice ${ }^{(65)}$ despite the fact that the Runx 2 mRNA level remained unchanged compared with wild-type mice. In contrast, the expression of Osterix was diminished in Runx2/Cbfa1-null mice. These results suggested that Osterix can be downstream of Runx2 during osteoblast differentiation $^{(65)}$. On the other hand, BMP-2induced Osterix expression can be independent of Runx2. Indeed, Osterix expression was still induced by BMP-2 treatment in Runx2-null cells ${ }^{(66)}$. Furthermore, it has been shown that during osteogenic lineage progression, in addition to the $\mathrm{BMP} /$ mothers against decapentaplegic homologue (SMAD) pathway, insulin-like growth factor-1 and MAPK signalling can mediate Osterix ${ }^{(63)}$.

EGCG has been demonstrated to have a stimulatory effect on osteogenesis of murine bone marrow mesenchymal stem cells. This green tea catechin after $48 \mathrm{~h}$ treatment, at concentrations of 1 and $10 \mu \mathrm{M}$, significantly up-regulated the expression of transcription factors Runx 2 and Osterix as well as osteoblast markers ALP and osteocalcin in cells compared with non-treated control cells. Moreover the longterm treatment of EGCG can increase ALP activity and eventually stimulate mineralisation, in spite of its inhibitory effect on proliferation ${ }^{(67)}$. The protein level of Runx 2 was also studied at different time points in the osteoblast-like cell line SaOS-2. After $48 \mathrm{~h}$ treatment Runx2 expression was decreased by EGCG at $1-5 \mu \mathrm{M}^{(68)}$. The ALP activity and mineralisation in SaOS-2 human osteoblasts treated with EGCG were increased compared with the control cells $^{(68)}$. Independent experiments have shown stimulating activities of EGCG on cells; however, Chen et al. observed the up-regulation of Runx 2 gene expression ${ }^{(67)}$ and Vali et al. the decrease of Runx2 protein expression ${ }^{(68)}$. It is common to observe that mRNA level does not correlate with protein level because expression of many genes can be regulated after transcription. To understand the molecular mechanisms it is necessary that transcript and protein levels are both assessed at the same time and in the same model.

Some isoflavones also have the capacity to increase ALP activity and mineralisation ${ }^{(42,43,69)}$. It has been shown that incubation with $1 \mathrm{nM}$-daidzein for $48 \mathrm{~h}$ increased the nuclear content of Runx2/Cbfa1 protein in porcine osteoblasts ${ }^{(69)}$. This effect was blocked by the oestrogen receptor inhibitor ICI 182.780, which indicates that Runx 2 activation is dependent on oestrogen-stimulated signalling.

Resveratrol (trans-3,4',5-trihydroxystilbene), a natural stilbene, has an impact on bone metabolism ${ }^{(49)}$ and, furthermore, trans-resveratrol has been shown to enhance the proliferation and differentiation of osteoblastic cells ${ }^{(70)}$. Dai et al. have demonstrated that this polyphenolic phytooestrogen at $1 \mu \mathrm{M}$ concentration could increase Runx 2 and

Table 1. Polyphenol regulation of transcription factors

\begin{tabular}{|c|c|c|c|c|}
\hline Reference & Model & Molecule treatment & Time exposure & Main findings \\
\hline \multicolumn{5}{|l|}{ Runx2 and Osterix } \\
\hline De Wilde et al. (2004) ${ }^{(69)}$ & Porcine OB & Daidzein $1 \mathrm{~nm}$ & $48 \mathrm{~h}$ & Runx2 (protein) $\uparrow$ \\
\hline Chen et al. $(2005)^{(67)^{\prime}}$ & MBMSC & EGCG $1-10 \mu \mathrm{M}$ & $48 \mathrm{~h}$ & $\begin{array}{l}\text { Runx2 (mRNA) } \uparrow \\
\text { Osterix (mRNA) } \uparrow\end{array}$ \\
\hline Dai et al. $(2007)^{(71)}$ & HBMSC & Resveratrol $1 \mu \mathrm{M}$ & Not shown & $\begin{array}{l}\text { Runx2 (mRNA) } \uparrow \\
\text { Osterix (mRNA) } \uparrow\end{array}$ \\
\hline Vali et al. $(2007)^{(68)}$ & SaOS-2 & EGCG $1-5 \mu \mathrm{M}$ & $48 \mathrm{~h}$ & Runx2 (protein) $\downarrow$ \\
\hline Zhao et al. (2008) ${ }^{(73)}$ & $\begin{array}{l}\text { MC3T3-E1 } \\
\text { Murine POB }\end{array}$ & Icariin $0.1 \mathrm{~nm}-10 \mu \mathrm{M}$ & 1,2 and $3 d$ & Runx2 (mRNA) $\uparrow$ \\
\hline \multicolumn{5}{|l|}{ AP-1 and NF-кB } \\
\hline Pang et al. $(2006)^{(79)}$ & Murine POB & Kaempferol $10 \mu \mathrm{M}+\mathrm{TNF} \alpha$ & $10 \mathrm{~min}$ & NF-кB activation $\downarrow$ \\
\hline Tokuda et al. (2007) ${ }^{(82)}$ & MC3T3-E1 & EGCG $10 \mu \mathrm{M}+\mathrm{PGF}_{2 \alpha}$ & $60 \mathrm{~min}$ & c-jun phosphorylation $\uparrow$ \\
\hline Lee et al. $(2008)^{(81)^{\prime}}$ & МСЗТЗ-Е1 & Emodin $2-5 \mu \mathrm{M}$ & $30 \mathrm{~min}$ & $\mathrm{NF}-\kappa \mathrm{B}$ activation $\uparrow$ \\
\hline Son et al. $(2008)^{(80)}$ & MC3T3-E1 & $\begin{array}{l}\text { Quercetin } 1-10 \mu \mathrm{M} \\
\text { Quercetin } 10 \mu \mathrm{M}+\mathrm{TNF} \alpha\end{array}$ & $6 \mathrm{~h}$ & $\begin{array}{l}\text { JunD translocation } \uparrow \\
\text { c-jun transclocation } \uparrow \\
\text { AP-1 DNA binding activity } \uparrow\end{array}$ \\
\hline
\end{tabular}

Runx2, runt-related transcription factor-2; OB, osteoblasts; $\uparrow$, increase; MBMSC, murine bone marrow mesenchymal stem cells; EGCG, (-)-epigallocatechin3-gallate; HBMSC, human bone marrow-derived mesenchymal stem cells; SaOS-2, sarcoma osteogenic cells; MC3T3-E1, murine osteoblastic cells; POB, primary osteoblasts; AP-1, activator protein-1; $\downarrow$, decrease. 
Osterix mRNA levels in human bone marrow-derived mesenchymal stem cells as well as one of their target genes - osteocalcin ${ }^{(71)}$. Addition of oestrogen receptor antagonist and ERK1/2 pathway inhibitors but not p38 MAPK pathway blockers attenuated resveratrol-induced gene expression $^{(71)}$.

Icariin, a flavonol glycoside isolated from herbs, was present in rat plasma after oral administration of Gushudan extract $^{(72)}$. This compound at different concentrations ranging from $0.1 \mathrm{nM}$ to $10 \mu \mathrm{M}$ induced osteogenic differentiation in MC3T3-E1 pre-osteoblasts and mouse primary osteoblasts ${ }^{(73)}$. Moreover, the expression of Runx2 was up-regulated in a dose- and time-dependent manner.

These data support the involvement of both Runx 2 and Osterix in the osteogenic effect of polyphenols, at a molecular level (Table 1).

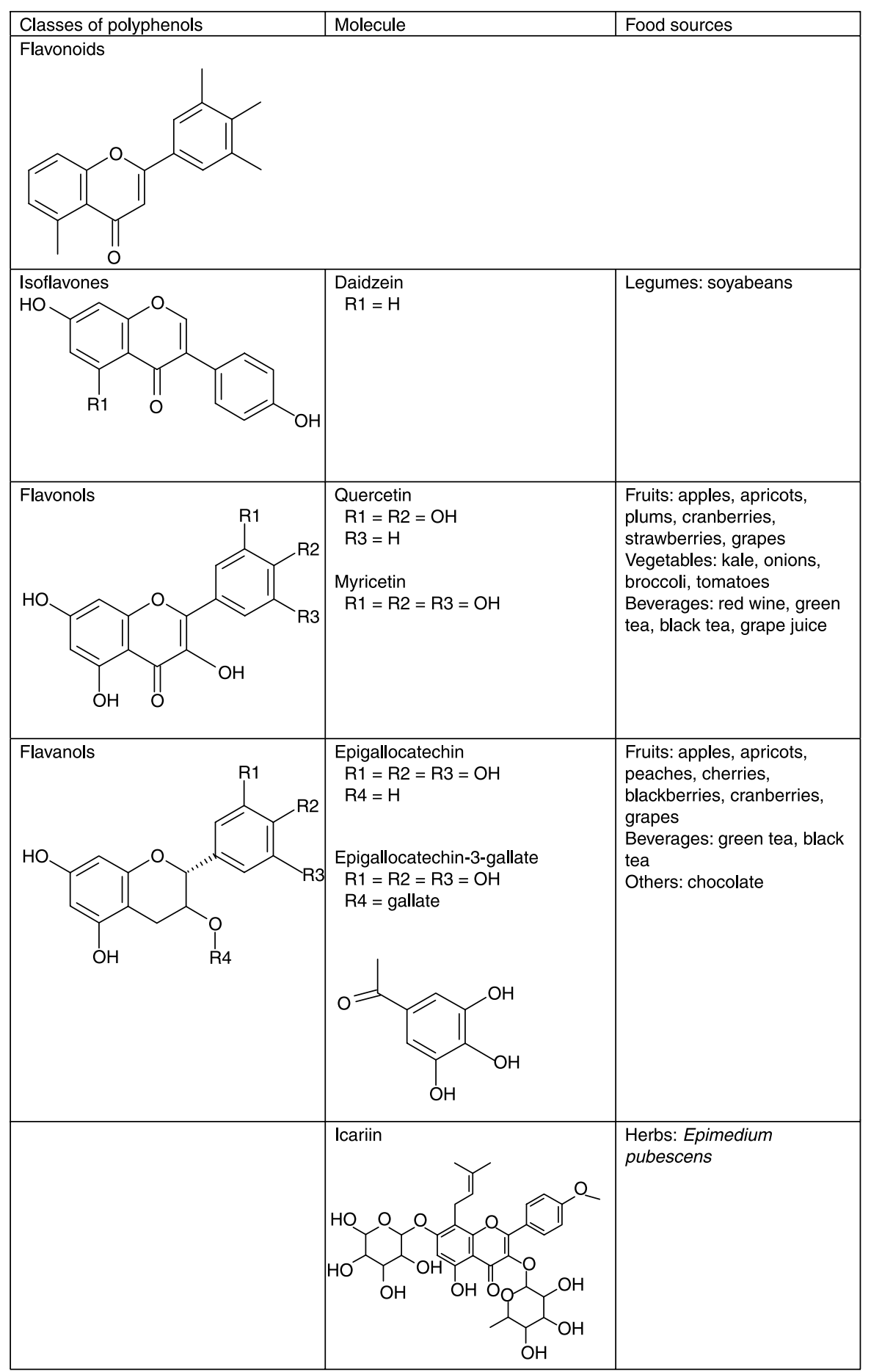

Fig. 4. Structure of studied polyphenols. 


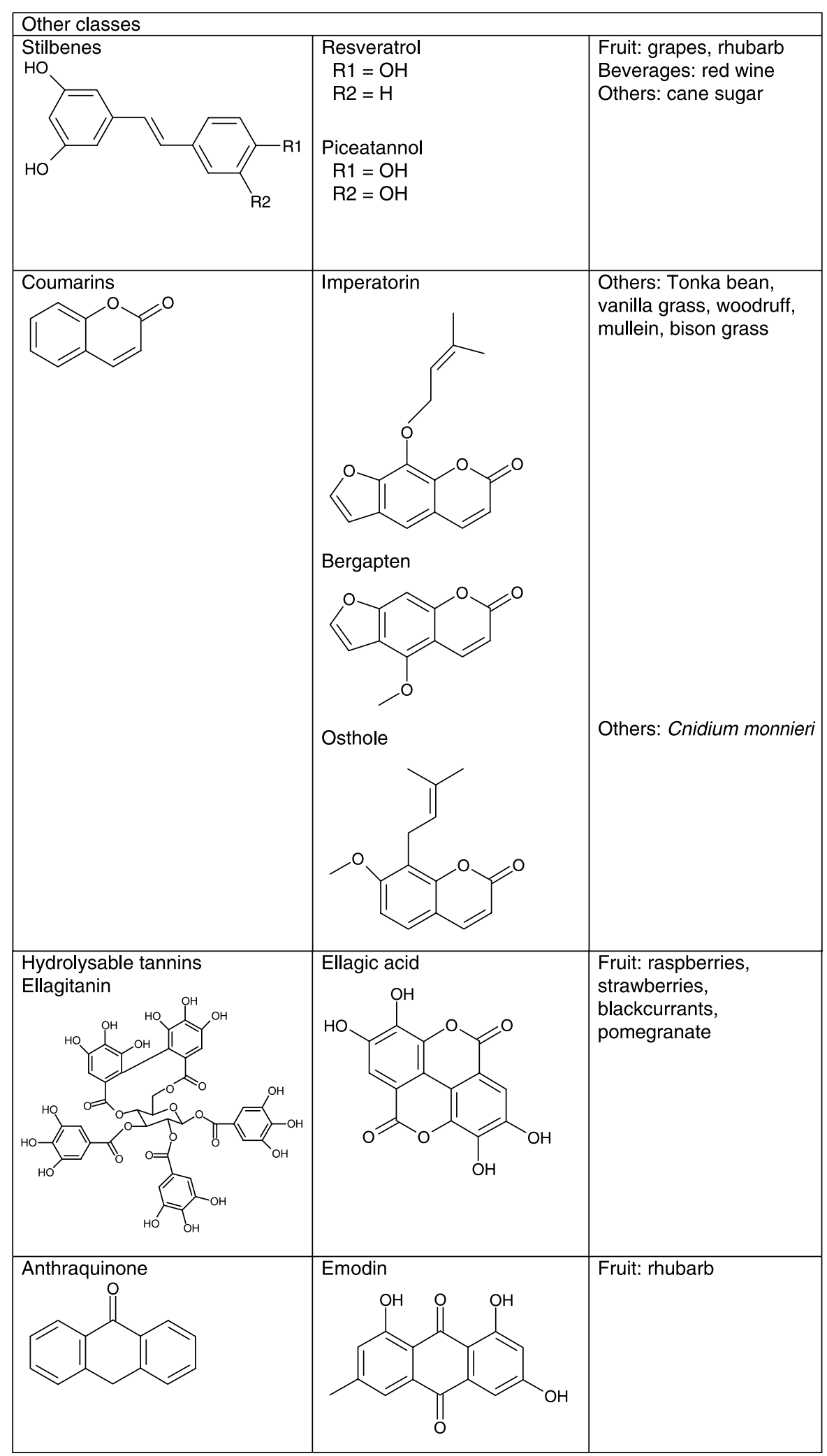

Fig. 4. Continued. 
Activator protein-1 and nuclear factor $\kappa B$. AP-1 and $\mathrm{NF}-\kappa \mathrm{B}$ are also implicated in the regulation of genes involved in many important biological processes in osteoblasts as well as osteoclasts. It was claimed that AP-1 can be induced by both oxidant and antioxidant conditions and it is primarily transcriptionally regulated $^{(74,75)}$. Activating transcription factor, Jun and Fos are the part of the dimeric transcription factor complex AP-1 and are known activators of proliferation, differentiation and apoptosis-related genes ${ }^{(76)}$. Many bone-specific genes such as ALP, osteocalcin and collagen I have AP-1 sites in their promoters ${ }^{(77)}$. Moreover, flavonoids are known to regulate $\mathrm{AP}-1$ and $\mathrm{NF}-\kappa \mathrm{B}$ activity occurring as final stages in signal-transduction cascades ${ }^{(44,77,78)}$. NF- $\kappa \mathrm{B}$, a dimeric transcription factor composed of Rel (cRel), RelA (p65), RelB, NF-кB1 (p50) and NF-кB2 (p52) recognises a common DNA sequence $(\kappa \mathrm{B}$ site). The activation of $\mathrm{NF}-\kappa \mathrm{B}$ in response to pro-oxidant conditions occurs by a post-translational mechanism, which involves dissociation of the inhibitory protein I $\mathrm{B}$ and its phosphorylation ${ }^{(74)}$. AP-1 and NF- $\kappa$ B transcription factors involved in MAPK signalling pathways are regulated by different mechanisms, but it appears that they could be activated simultaneously by the same agents. Thus these transcription factors work together and may modulate the activity of each other ${ }^{(75)}$.

Pang et al. ${ }^{(79)}$ have reported that kaempferol but not quercetin (both at $10 \mu \mathrm{M}$ ) blocked $\mathrm{TNF} \alpha$-induced $\mathrm{NF}-\kappa \mathrm{B}$ (p65) nuclear translocation in primary osteoblasts and inhibited the production of osteoclastogenic cytokines IL-6 and monocyte chemotactic protein-1. Recently, it has been demonstrated that quercetin $(1-10 \mu \mathrm{M})$ could accelerate $\mathrm{TNF} \alpha$-mediated apoptosis in MC3T3-E1 cells via activation of caspases and the JNK pathway ${ }^{(80)}$. DNA binding activity of AP-1 and nuclear translocation of c-jun protein were increased after treating the MC3T3-E1 cells with $\mathrm{TNF} \alpha$ and these effects were augmented in the presence of quercetin $^{(80)}$. Quercetin at $10 \mu \mathrm{M}$ alone did not have any effect on the nuclear induction of c-jun but was able to increase the level of Jun D translocation. However, this quercetin effect could not be found in primary osteoblasts ${ }^{(80)}$, this being consistent with the findings of Pang et al. ${ }^{(79)}$.

Another phenolic compound, emodin (anthraquinone), present in the roots and bark of numerous plants of the genus Rhamus, stimulated differentiation and mineralisation and was able to activate NF- $\mathrm{BB}$ but not AP-1 in MC3T3-E1 cells ${ }^{(81)}$. Moreover, the assay to identify compounds activating BMP-2 promoter was performed after $2 \mathrm{~d}$ emodin treatment. Emodin at the range of $5-10 \mu \mathrm{M}$ increased the activation of BMP-2 promoter containing NF- $\kappa \mathrm{B}$ response element but not that without $N F-\kappa B^{(81)}$. It was suggested that NF- $\kappa \mathrm{B}$ could be required for emodin anabolic activity.

The effect of the catechin EGCG on $\mathrm{PGF}_{2 \alpha}$-stimulated vascular endothelial growth factor synthesis via stressactivated protein kinase (SAPK)/JNK activation was studied in MC3T3-E1 cells ${ }^{(82)}$. It has been shown that $60 \mathrm{~min}$ of pre-treatment with $10 \mu \mathrm{M}-\mathrm{EGCG}$ amplified $\mathrm{PGF}_{2 \alpha}$-induced phosphorylation of $\mathrm{c}$-jun which is a part of the AP-1 complex and well known as a downstream effector of SAPK/JNK ${ }^{(82)}$.
Regarding all the reported studies dealing with polyphenols at nutritional and physiological levels, there is good evidence that these compounds are able to interact with some well-known osteoblast-related transcription factors including Runx2, Osterix, AP-1 and NF-кB (Table 1) and possibly with all BMP-activated signalling pathways. Even though all the studies reported here provide some evidence of regulatory activity of specific transcription factors, it is difficult to make conclusions about precise molecular mechanisms of phenolics in osteoblastic cells. Moreover, if the present review focuses on osteoblasts, it is important to highlight the interface between polyphenols, bone formation and resorption. Indeed, it has been demonstrated that NF-кB and AP-1 are transcription factors also involved in osteoclast differentiation and their inhibition could play a role in the decrease of osteoclastogenesis.

\section{A story beyond and around bone morphogenetic protein- stimulated pathways}

Recent studies have shown that BMP induce osteoblast differentiation and play an important role in osteogenesis during development and in adult life ${ }^{(83)}$. Furthermore, BMP stimulate the formation of mineralised bone-like nodules ${ }^{(84)}$. These proteins, by an autocrine action, may activate different signalling cascades. BMP regulatory molecules can transmit signals through SMAD-dependent and SMAD-independent pathways, including ERK, JNK, and p38 MAP kinase pathways ${ }^{(85)}$. Members of the BMP family can bind to various serine/threonine kinase receptors I and II which are necessary for signal transduction ${ }^{(86)}$. Moreover, BMP signalling can interact with other pathways such as transforming growth factor- $\beta$, Notch, Wnt, signal transducer and activator of transcription (STAT) and MAPK by cross-talk with them ${ }^{(85)}$. Because BMP stimulate new bone formation ${ }^{(87)}$, indicating a clear role in the regulation of osteoblast function, they represent molecular targets used to identify new agents to prevent osteoporosis ${ }^{(5)}$. BMP-2 is one of the major proteins implicated, as an important regulator, in bone metabolism.

Regulation of BMP signalling is important for cell functions and BMP activity can be regulated by many mechanisms (intra- and/or extracellular; for a review, see Canalis et al. $\left.{ }^{(83)}\right)$. One mechanism is regulation by extracellular antagonists such as noggin which can bind BMP and thus prevent stimulation of BMP receptors and cell signalling ${ }^{(88,89)}$. Noggin selectively blocks BMP function; thus it can be used as a tool in cell biology to inhibit the BMP pathway ${ }^{(90)}$.

It has been shown that some phenolic compounds such as coumarin derivatives ${ }^{(91,92)}$, piceatannol (stilbene) ${ }^{(93)}$, resveratrol (stilbene) $)^{(94)}$ and myricetin (flavonoid) ${ }^{(95)}$ increase BMP-2 production in osteoblastic cells (Table 2). Moreover, the ALP activity and osteocalcin production induced by these compounds was inhibited by noggin, suggesting that BMP-2 signalling is involved in osteoblast differentiation. Myricetin $\left(3,3^{\prime}, 4^{\prime}, 4,5,5^{\prime}, 7\right.$-hexahydroxyflavone), a flavonoid present in grape juice and red wine, as well as piceatannol (3,3',4,5'-tetrahydroxy-trans-stilbene) found in the skins of grapes, rhubarb and cane sugar exhibit 
potential healthy effects on organisms ${ }^{(96,97)}$. More specifically, myricetin $(1-20 \mu \mathrm{M})^{(95)}$ and piceatannol $(0 \cdot 1-20 \mu \mathrm{M})^{(93)}$ dose dependently stimulated osteoblast differentiation at various stages and also mineralisation in both human osteoblastic cell line hFOB and human osteosarcoma cell line MG-63. It was demonstrated that myricetin induced phosphorylation of SMAD1/5/8 complex and p38 protein which can be abrogated by noggin pretreatment. Addition of the specific inhibitor of p38 decreased ALP activity and osteocalcin secretion as well as phosphorylation of $\mathrm{p} 38$ in cells treated with myricetin. In this experiment, myricetin through BMP-2 activated not only the SMAD-dependent pathway but also the p38 kinase pathway that has been implicated in differentiation ${ }^{(95)}$.

Coumarin derivates such as imperatorin and bergapten increased BMP-2 gene expression in a time- and dosedependent manner but not BMP-4 or BMP-7 in primary osteoblasts ${ }^{(92)}$. On the contrary, icariin (a flavonol glycoside) induced the expression of BMP-4 in osteoblasts ${ }^{(73)}$. Coumarin derivatives increased phosphorylation of SMAD1/5/8, p38 and ERK in a time-dependent manner. Pre-treatment with a p38 inhibitor and MAPK or ERK kinase (MEK) inhibitor markedly diminished coumarininduced p38 and ERK1/2 phosphorylation, as well as BMP2 gene expression ${ }^{(92)}$. It has been observed that another coumarin derivate osthole (7-methoxy-8-isopentenoxycoumarin), present in Chinese medicine, used the same mechanisms to induce osteoblast differentiation in $\mathrm{hFOB}$ and MG-63 cells ${ }^{(91)}$. Thus, BMP-2 protein appears to be required for coumarin-mediated maturation of osteoblasts.

Lee et al. have shown that emodin at the range of $2-5 \mu \mathrm{M}$ accelerated osteoblast differentiation via stimulation of BMP-2 gene expression and the activation of PI3KAKT/MAP kinases (especially JNK and p38). These effects were abolished by a PI3K inhibitor, suggesting that emodin-induced BMP-2 expression was dependent on PI3K-AKT/MAP kinase cascades ${ }^{(81)}$.

Results from these studies have shown that polyphenols were able to influence osteoblast differentiation and mineralisation through an increase in BMP-2 production, which in turn could activate phosphorylation of specific proteins (SMAD, p38, ERK1/2). Taken together, polyphenols can affect osteoblast function by the complex network of BMP-related signalling pathways (Table 2).

\section{What about polyphenols and oestrogen receptor signalling?}

Both oestrogen $\alpha$ and $\beta$ receptors can be found in osteoblasts $^{(98-100)}$. Oestrogens can modulate gene expression through genomic and/or non-genomic mechanisms. Genomic transcriptional regulation is achieved through recruitment of oestrogen receptors to the promoter region of the target gene, either directly through interaction with DNA sequences (i.e. oestrogen receptor element) or through protein-protein interaction with other transcriptional factors such as AP-1 and NF- $\mathrm{BB}^{(101,102)}$. Non-genomic action (called 'rapid') can also initiate gene transcription but through oestrogen activation of signal-transduction pathways which are insensitive to inhibitors of transcription and translation $^{(103)}$. However, it is possible that different oestrogen receptor ligands induce conformational changes in oestrogen receptors, blocking the activation of signalling cascades $^{(104)}$. The anti-apoptotic effects of oestrogens and oestrogenic compounds on osteoblastic cells are mediated by oestrogen receptor-mediated ERK pathway activation, which is distinct from genomic actions of oestrogen receptors ${ }^{(105-109)}$. The oestrogen receptor-oestrogen complex interacts with Src tyrosine kinase and results in the rapid activation of ERK. ERK in turn is responsible for downstream activation of Elk-1, cAMP responsive element binding protein (CREB) and CCAAT/enhancer binding protein- $\beta$, transcription factors involved in anti-apoptotic effects of sex steroids on osteoblasts. Also inactivation by phosphorylation of a pro-apoptotic protein Bad takes place. On the other hand, JNK activity and downstream transcription driven by transcription factor AP-1 are downregulated via a non-genomic oestrogen receptor-mediated pathway ${ }^{(99,110)}$. In general, oestrogen acts on osteoblasts by modulating the activity of cytosolic kinases and subsequent post-transcriptional modification of transcription factors,

Table 2. Interaction of polyphenols with the bone morphogenetic protein (BMP) pathway

\begin{tabular}{|c|c|c|c|c|}
\hline Reference & Model & Molecule treatment & Time exposure & Main findings \\
\hline Kuo et al. $(2005)^{(91)}$ & $\begin{array}{l}\text { hFOB } \\
\text { MG-63 }\end{array}$ & Coumarin (osthole) $10 \mu \mathrm{M}$ & $3,6,12,24 \mathrm{~h} 1 \mathrm{~h}$ & $\begin{array}{l}\text { BMP-2 } \uparrow \\
\text { SMAD } 1 / 5 / 8, \text { p38, ERK } \\
\quad \text { phosphorylation } \uparrow\end{array}$ \\
\hline Chang et al. $(2006)^{(93)}$ & $\begin{array}{l}\text { hFOB } \\
\text { MG-63 }\end{array}$ & Piceatannol 1-20 $\mu \mathrm{M}$ & $6,12,24 \mathrm{~h}$ & BMP-2 $\uparrow$ \\
\hline Hsu et al. $(2007)^{(95)}$ & $\begin{array}{l}\text { hFOB } \\
\text { MG-63 }\end{array}$ & Myricetin 1-20 $\mu \mathrm{M}$ & $3,6,12 \mathrm{~h}$ & $\begin{array}{l}\text { BMP-2 } \uparrow \\
\text { SMAD } 1 / 5 / 8, \text { p38 } \\
\text { phosphorylation } \uparrow\end{array}$ \\
\hline Su et al. $(2007)^{(94)}$ & $\begin{array}{l}\text { POB } \\
\text { MC3T3-E1 } \\
\text { MG-63 }\end{array}$ & Resveratrol $0.1-10 \mu \mathrm{M}$ & $48 \mathrm{~h}$ & BMP-2 $\uparrow$ \\
\hline Lee et al. $(2008)^{(81)}$ & MC3T3-E1 & Emodin $5-10 \mu \mathrm{M}$ & $48 \mathrm{~h}$ & Activation of BMP-2 promoter $\uparrow$ \\
\hline \multirow[t]{2}{*}{ Tang et al. $(2008)^{(92)}$} & Rat POB & $\begin{array}{l}\text { Coumarin (bergapten, } \\
\text { imperatorin) } 0.3-10 \mu \mathrm{M}\end{array}$ & $12 \mathrm{~h}$ & BMP-2 $\uparrow$ \\
\hline & & & $1,3,6,12,24 \mathrm{~h}$ & $\begin{array}{c}\text { SMAD } 1 / 5 / 8, \text { p38, ERK } \\
\text { phosphorylation } \uparrow\end{array}$ \\
\hline Zhao et al. $(2008)^{(73)}$ & МС3ТЗ-Е1 & Icariin $0.1 \mathrm{nM}-10 \mu \mathrm{M}$ & $3 d$ & $\mathrm{BMP}-4 \uparrow$ \\
\hline
\end{tabular}

hFOB, fetal human osteoblastic cell line; $\uparrow$, increase; MG-63, human osteosarcoma cell line; SMAD, mothers against decapentaplegic homologue; ERK, extracellular signal-regulated kinase; POB, primary osteoblasts; MC3T3-E1, murine osteoblastic cells. 
which results in up- or down-regulation of gene expression $^{(98)}$.

Isoflavones such as daidzein and genistein are classified as phyto-oestrogens and are thought to act via the oestrogen receptors to improve bone health. Plant-derived flavonoids and phyto-oestrogens can change oestrogen receptor- $\alpha$ and oestrogen receptor- $\beta$ activities in different ways and act as oestrogen agonists and/or antagonists depending on tissue type and molecule concentration ${ }^{(53)}$. Some nutritional flavonoids such as quercetin and naringenin acting as oestrogen-mimetics can activate p38/MAPK in the presence of oestrogen receptor- $\beta^{(111)}$. These molecules have an antioxidant function in plants but they could act on oestrogen receptors as agonists and/or antagonists in the organism ${ }^{(112)}$. It has been shown that isoflavones have anabolic effects on bone metabolism by stimulating osteoblasts and decreasing osteoclast functions ${ }^{(42)}$. The oestrogenic properties of isoflavones were investigated by Chen et al. ${ }^{(113)}$ in two $\mathrm{hFOB}$ osteoblastic cell lines expressing different levels of oestrogen receptors. The expression and the production of osteoclastogenesis-regulatory cytokines such as IL-6 and OPG were dependent on the level of oestrogen receptors. The human fetal osteoblastic cell lines hFOB1.19 (400 oestrogen receptors/nucleus) and hFOB/ER9 (8000 oestrogen receptors/nucleus) were treated with $10 \mathrm{nM}-17 \beta$-oestradiol, $0 \cdot 1-10 \mathrm{nM}$-genistein or daidzein and/or $10 \mu \mathrm{M}$-ICI (inhibitor of oestrogen receptor) for $48 \mathrm{~h}$. IL-6 protein production was decreased by about $30-40 \%$ in hFOB 1.19 cells and $40-60 \%$ in hFOB/ER9 cells by isoflavone treatments in comparison with the non-treated control cells. The effect of genistein and daidzein was slightly dose dependent and was greater in cells that were most abundant in oestrogen receptors (hFOB/ER9) ${ }^{(113)}$. Moreover, it has been shown that daidzein could enhance the cell content of oestrogen receptor- $\beta$, which seems to be involved in the daidzein action in osteoblasts ${ }^{(69)}$.

Concerning other polyphenols, ellagitannins and ellagic acid, mainly found in red fruit, such as raspberries, strawberries, blackcurrants and pomegranate ${ }^{(114)}$, are also oestrogenic but have not been studied as much. It has been shown that inhibitors of oestrogen receptors decreased the activity of ALP and mineralisation induced by ellagic acid in osteoblastic cells ${ }^{(115)}$. Indeed, ellagic acid may act as a natural selective oestrogen receptor modulator ${ }^{(115)}$ and may act through oestrogen receptors, but the molecular mechanisms are not well known and they need to be further investigated.

Resveratrol enhanced proliferation and osteoblastic differentiation in a dose-dependent manner in human bone marrow-derived mesenchymal stem cells $^{(71)}$. This stimulating effect could be induced by an oestrogen receptor-dependent mechanism coupled to ERK1/2 activation. Moreover, ICI completely abolished the resveratrol-induced phosphorylation of ERK1/2 and p38, suggesting that oestrogen receptors were implicated in resveratrol MAPK activation ${ }^{(71)}$.

As reported above, some phenolic compounds can act on bone remodelling through the oestrogen receptors as well as via non-oestrogenic mechanisms, for example, resveratrol. This increases the difficulty associated with elucidating the molecular mechanisms of action of a given compound in a specific cell or tissue.

\section{Polyphenols and osteoprotegerin/receptor activator of nuclear factor $-\kappa B$ ligand}

Osteoblasts are implicated in the regulation of osteoclastogenesis through the OPG/RANKL/RANK regulatory system. OPG is a member of the TNF receptor family. This protein was characterised as an essential osteoclast differentiation factor expressed by osteoblastic/stromal cells and is involved in cell development ${ }^{(116,117)}$. Osteoblasts produce OPG, which acts as a decoy receptor for RANKL and thereby neutralises its function in osteoclastogenesis. Indeed, RANKL activates osteoclastogenesis by binding to RANK while OPG may inhibit the activation of osteoclasts and promote osteoclast apoptosis. Bone homeostasis seems to depend on the local RANKL:OPG ratio ${ }^{(118,119)}$ and a mechanism involving the RANKL/OPG system is plausible because RANK is present in pre-osteoclastic cells ${ }^{(120)}$.

Within the polyphenols there is most evidence to show that isoflavones are able to influence OPG/RANKL/RANK regulatory machinery implicated in the osteoblast and osteoclast relationship. Daidzein and $17 \beta$-oestradiol at low concentration (1 nM) stimulated osteoblast differentiation and were able to increase OPG secretion into the medium. Daidzein and genistein at physiological concentrations ( 0.1 and $10 \mathrm{nM})$ up-regulated OPG gene expression, but RANKL expression was not detectable in human osteoblastic cell lines ${ }^{(113)}$. Moreover, daidzein enhanced RANKL protein secretion and content in the membrane in porcine osteoblasts ${ }^{(69)}$. This stimulatory effect was reversed by ICI, suggesting that the RANKL:OPG ratio is dependent on the oestrogen receptor pathway ${ }^{(69,113)}$. It is possible that $\mathrm{OPG}$ and RANKL secretion induced by daidzein leads to an increase in the binding capacity of OPG to RANKL. In consequence, the amount of RANKL available to induce osteoclast formation and differentiation is reduced ${ }^{(69)}$

However, Pang et al. demonstrated, in mouse primary calvaria osteoblasts, that kaempferol and quercetin dose dependently $(5-20 \mu \mathrm{M})$ inhibited RANKL-induced expression of osteoclastic differentiation markers, which led to a decrease in RANKL-induced formation of multinucleated osteoclasts ${ }^{(79)}$. The relationship between osteoblasts, osteoclasts and phytochemicals remains to be further investigated.

\section{Effects of polyphenol extracts on osteoblasts}

The effects of polyphenols on osteoblasts were mostly studied using pure molecules, unfortunately most of the time in aglycone forms. However, individuals consume not isolated molecules but fruit and vegetables, which are rich in many different polyphenols. It could be thus interesting to assess effects of phenolic mixtures on osteoblast function. It is important to take into consideration that polyphenols are metabolised before reaching the target cells.

The only available data with respect to osteoblasts are from $\mathrm{Bu}$ et al. who studied the influence of dried plum polyphenol extract at concentrations of $2 \cdot 5,5$ and $10 \mu \mathrm{g} / \mathrm{ml}$ on MC3T3-E1 cells under normal and inflammatory conditions ${ }^{(121)}$. This extract, non-toxic for osteoblasts, was able to stimulate ALP activity and mineralise nodule formation. The plum extract was not 


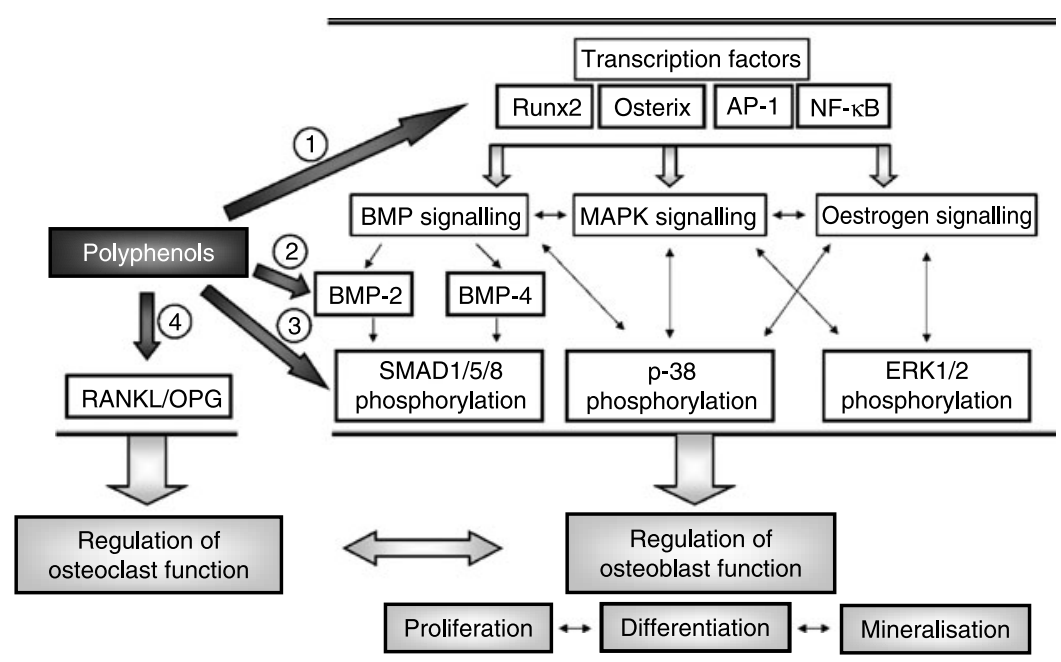

Fig. 5. Putative mechanisms of action of polyphenols on osteoblast signalling. Runx2, runt-related transcription factor-2; AP-1, activator protein-1; BMP, bone morphogenetic protein; MAPK, mitogen-activated protein kinase; RANKL, receptor activator of NF-кB ligand; OPG, osteoprotegerin; SMAD, mothers against decapentaplegic homologue; ERK, extracellular signal-regulated kinase. Polyphenols: (1), daidzein, (-)-epigallocatechin-3-gallate, emodin, icariin, kaempferol, resveratrol, quercetin; (2), coumarins, emodin, icariin, myricetin, piceatannol, resveratrol; (3), coumarins, myricetin; (4), daidzein, genistein, kaempferol, quercetin.

able to alter the expression of the transcription factors Runx2 and Osterix nor genes implicated in osteoclast regulation such as RANKL and OPG. However, this extract could restore Runx2 and Osterix expression in cells that had been pre-treated with TNF $\alpha$ (inflammatory condition) and as a result exhibited reduced Runx 2 and Osterix expression. The extract also suppressed the TNF $\alpha$-induced up-regulation of RANKL expression ${ }^{(121)}$, but OPG expression was not affected by any treatments. These results suggest that consumption of dried plums could modulate both bone formation and resorption but the molecular mechanisms are poorly elucidated.

\section{Conclusions}

Regarding osteoblasts, polyphenols can act on these cells at different stages including proliferation, differentiation and mineralisation ${ }^{(9)}$. Physiological effects in response to polyphenols have been observed but the molecular mechanisms schematically presented in Fig. 5 are not fully understood. Many signalling pathways, often talking to each other, need to be activated to stimulate cell functions, and it is expected that many years of scientific work will be required to elucidate the exact molecular mechanisms by which polyphenols affect osteoblast regulation. Moreover, it is important to keep in mind that polyphenols may act through not only an action on osteoblasts but also on osteoclasts. These combined effects are helpful to maintain a balance in bone remodelling, a key endpoint in the management of osteoporosis.

\section{Acknowledgements}

The authors have no conflicts of interest to declare.

\section{References}

1. Pettifor JM, Prentice A \& Cleaton-Jones P (2003) The skeletal system. In Nutrition and Metabolism, pp. 247-283 [MJ Gibney, IA Macdonald and HM Roche, editors]. Oxford: Blackwell Publishing.

2. Sommerfeldt DW \& Rubin CT (2001) Biology of bone and how it orchestrates the form and function of the skeleton. Eur Spine J 10, Suppl. 2, S86-S95.

3. Simon LS (2005) Osteoporosis. Clin Geriatr Med 21, 603-629, viii.

4. Suzuki A, Sekiguchi S, Asano S, et al. (2008) Pharmacological topics of bone metabolism: recent advances in pharmacological management of osteoporosis. J Pharmacol Sci 106, 530-535.

5. Mundy GR (2006) Nutritional modulators of bone remodeling during aging. Am J Clin Nutr 83, S427-S430.

6. New SA (1999) Bone health: the role of micronutrients. Br Med Bull 55, 619-633.

7. Ilich JZ \& Kerstetter JE (2000) Nutrition in bone health revisited: a story beyond calcium. J Am Coll Nutr 19, 715-737.

8. Heaney RP (2007) Bone health. Am J Clin Nutr 85, 300S-303S.

9. Habauzit V \& Horcajada MN (2008) Phenolic phytochemicals and bone. Phytochem Rev 7, 313-344.

10. Marie PJ (2008) Transcription factors controlling osteoblastogenesis. Arch Biochem Biophys 473, 98-105.

11. Bringhurst FR, Demay MB, Krane SM, et al. (2005) Bone and mineral metabolism in health and disease. In Harrison's Principles of Internal Medicine, pp. 2238-2249 [DL Kasper, E Braunwald and AS Fauci, editors]. New York: McGraw-Hill.

12. Katagiri T \& Takahashi N (2002) Regulatory mechanisms of osteoblast and osteoclast differentiation. Oral Dis 8, $147-159$.

13. Strewler GJ (2001) Local and systemic control of the osteoblast. J Clin Invest 107, 271-272.

14. Baylink DJ, Finkelman RD \& Mohan S (1993) Growth factors to stimulate bone formation. J Bone Miner Res $\mathbf{8}$, Suppl. 2, S565-S572. 
15. Kalajzic I, Staal A, Yang WP, et al. (2005) Expression profile of osteoblast lineage at defined stages of differentiation. J Biol Chem 280, 24618-24626.

16. Yamaguchi A, Komori T \& Suda T (2000) Regulation of osteoblast differentiation mediated by bone morphogenetic proteins, hedgehogs, and Cbfa1. Endocr Rev 21, 393-411.

17. Westendorf JJ, Kahler RA \& Schroeder TM (2004) Wnt signaling in osteoblasts and bone diseases. Gene 341, 19-39.

18. Niu TH \& Rosen CJ (2005) The insulin-like growth factor-I gene and osteoporosis: a critical appraisal. Gene 361, $38-56$.

19. Huang W, Yang S, Shao J, et al. (2007) Signaling and transcriptional regulation in osteoblast commitment and differentiation. Front Biosci 12, 3068-3092.

20. Stein GS \& Lian JB (1993) Molecular mechanisms mediating proliferation differentiation interrelationships during progressive development of the osteoblast phenotype. Endocr Rev 14, 424-442.

21. Ehrlich PJ \& Lanyon LE (2002) Mechanical strain and bone cell function: a review. Osteoporos Int 13, 688-700.

22. Burger EH, Klein-Nulend J \& Smit TH (2003) Strainderived canalicular fluid flow regulates osteoclast activity in a remodelling osteon - a proposal. J Biomech 36, $1453-1459$.

23. Ash P, Loutit JF \& Townsend KM (1980) Osteoclasts derived from haematopoietic stem cells. Nature 283, 669-670.

24. Felix R, Cecchini MG \& Fleisch H (1990) Macrophage colony stimulating factor restores in vivo bone resorption in the op/op osteopetrotic mouse. Endocrinology 127, 2592-2594

25. Kodama H, Yamasaki A, Nose M, et al. (1991) Congenital osteoclast deficiency in osteopetrotic (op/op) mice is cured by injections of macrophage colony-stimulating factor. $J$ Exp Med 173, 269-272.

26. Kodama H, Nose M, Niida S, et al. (1991) Essential role of macrophage colony-stimulating factor in the osteoclast differentiation supported by stromal cells. J Exp Med 173, $1291-1294$

27. Sambrook P \& Cooper C (2006) Osteoporosis. Lancet 367, 2010-2018.

28. Scalbert A, Manach C, Morand C, et al. (2005) Dietary polyphenols and the prevention of diseases. Crit Rev Food Sci Nutr 45, 287-306.

29. Manach C, Williamson G, Morand C, et al. (2005) Bioavailability and bioefficacy of polyphenols in humans. I. Review of 97 bioavailability studies. Am J Clin Nutr 81, 230S-242S.

30. Kroon PA, Clifford MN, Crozier A, et al. (2004) How should we assess the effects of exposure to dietary polyphenols in vitro? Am J Clin Nutr 80, 15-21.

31. Manach C, Scalbert A, Morand C, et al. (2004) Polyphenols: food sources and bioavailability. Am J Clin Nutr 79, 727-747.

32. Williamson G, Barron D, Shimoi K, et al. (2005) In vitro biological properties of flavonoid conjugates found in vivo. Free Radic Res 39, 457-469.

33. Serra H, Mendes T, Bronze MR, et al. (2008) Prediction of intestinal absorption and metabolism of pharmacologically active flavones and flavanones. Bioorg Med Chem 16, 4009-4018.

34. O'Leary KA, Day AJ, Needs PW, et al. (2001) Flavonoid glucuronides are substrates for human liver $\beta$-glucuronidase. FEBS Lett 503, 103-106.

35. Khlebnikov AI, Schepetkin IA, Domina NG, et al. (2007) Improved quantitative structure-activity relationship models to predict antioxidant activity of flavonoids in chemical, enzymatic, and cellular systems. Bioorg Med Chem 15, 1749-1770.

36. Loke WM, Proudfoot JM, McKinley AJ, et al. (2008) Quercetin and its in vivo metabolites inhibit neutrophilmediated low-density lipoprotein oxidation. J Agric Food Chem 56, 3609-3615.

37. Tribolo S, Lodib F, Connor C, et al. (2008) Comparative effects of quercetin and its predominant human metabolites on adhesion molecule expression in activated human vascular endothelial cells. Atherosclerosis 197, $50-56$.

38. Suri S, Taylor MA, Verity A, et al. (2008) A comparative study of the effects of quercetin and its glucuronide and sulfate metabolites on human neutrophil function in vitro. Biochem Pharmacol 76, 645-653.

39. Schroeter H, Boyd C, Spencer JP, et al. (2002) MAPK signaling in neurodegeneration: influences of flavonoids and of nitric oxide. Neurobiol Aging 23, 861-880.

40. Williams RJ, Spencer JP \& Rice-Evans C (2004) Flavonoids: antioxidants or signalling molecules? Free Radic Biol Med 36, 838-849.

41. Spinozzi F, Pagliacci MC, Migliorati G, et al. (1994) The natural tyrosine kinase inhibitor genistein produces cell cycle arrest and apoptosis in Jurkat T-leukemia cells. Leuk Res 18, 431-439.

42. Yamaguchi M (2002) Isoflavone and bone metabolism: its cellular mechanism and preventive role in bone loss. $J$ Health Sci 48, 209-222.

43. Sugimoto E \& Yamaguchi M (2000) Stimulatory effect of daidzein in osteoblastic MC3T3-E1 cells. Biochem Pharmacol 59, 471-475.

44. Orzechowski A, Ostaszewski P, Jank M, et al. (2002) Bioactive substances of plant origin in food - impact on genomics. Reprod Nutr Dev 42, 461-477.

45. Katiyar SK, Afaq F, Azizuddin K, et al. (2001) Inhibition of UVB-induced oxidative stress-mediated phosphorylation of mitogen-activated protein kinase signaling pathways in cultured human epidermal keratinocytes by green tea polyphenol (-)-epigallocatechin-3-gallate. Toxicol Appl Pharmacol 176, 110-117.

46. Balasubramanian S, Efimova T \& Eckert RL (2002) Green tea polyphenol stimulates a Ras, MEKK1, MEK3, and p38 cascade to increase activator protein 1 factor-dependent involucrin gene expression in normal human keratinocytes. J Biol Chem 277, 1828-1836.

47. Bradamante S, Barenghi L \& Villa A (2004) Cardiovascular protective effects of resveratrol. Cardiovasc Drug Rev 22, $169-188$.

48. Aziz MH, Kumar R \& Ahmad N (2003) Cancer chemoprevention by resveratrol: in vitro and in vivo studies and the underlying mechanisms (review). Int J Oncol 23, $17-28$.

49. King RE, Bomser JA \& Min DB (2006) Bioactivity of resveratrol. Compr Rev Food Sci Food Safety 5, 65-70.

50. Das S, Tosaki A, Bagchi D, et al. (2006) Potentiation of a survival signal in the ischemic heart by resveratrol through p38 mitogen-activated protein kinase/mitogenand stress-activated protein kinase $1 / \mathrm{cAMP}$ response element-binding protein signaling. $J$ Pharmacol Exp Ther 317, 980-988.

51. Linder MW, Falkner KC, Srinivasan G, et al. (1999) Role of canonical glucocorticoid responsive elements in modulating expression of genes regulated by the arylhydrocarbon receptor. Drug Metab Rev 31, 247-271. 
52. Klinge CM (2001) Estrogen receptor interaction with estrogen response elements. Nucleic Acids Res 29, 2905-2919.

53. Kuiper GG, Lemmen JG, Carlsson B, et al. (1998) Interaction of estrogenic chemicals and phytoestrogens with estrogen receptor $\beta$. Endocrinology 139, 4252-4263.

54. Bennetau-Pelissero C, Latonnelle K, Sequeira A, et al. (2000) Phytoestrogens, endocrine disrupters from food. Analusis 28, 763-775.

55. Niehrs C \& Meinhardt H (2002) Developmental biology modular feedback. Nature 417, 35-36.

56. Noe V, Penuelas S, Lamuela-Raventos RM, et al. (2004) Epicatechin and a cocoa polyphenolic extract modulate gene expression in human Caco-2 cells. J Nutr 134, 2509-2516.

57. Ko CH, Shen SC, Lin HY, et al. (2002) Flavanones structure-related inhibition on TPA-induced tumor promotion through suppression of extracellular signal-regulated protein kinases: involvement of prostaglandin E-2 in anti-promotive process. J Cell Physiol 193, 93-102.

58. Yang CS, Lambert JD, Hou Z, et al. (2006) Molecular targets for the cancer preventive activity of tea polyphenols. Mol Carcinog 45, 431-435.

59. O'Prey J, Brown J, Fleming J, et al. (2003) Effects of dietary flavonoids on major signal transduction pathways in human epithelial cells. Biochem Pharmacol 66, 2075-2088.

60. Vittal R, Selvanayagam ZE, Sun Y, et al. (2004) Gene expression changes induced by green tea polyphenol (-)epigallocatechin-3-gallate in human bronchial epithelial 21BES cells analyzed by DNA microarray. Mol Cancer Ther 3, 1091-1099.

61. Muller M \& Kersten S (2003) Nutrigenomics: goals and strategies. Nat Rev Genet 4, 315-322.

62. Komori T (2005) Regulation of skeletal development by the Runx family of transcription factors. J Cell Biochem 95, 445-453.

63. Celil AB, Hollinger JO \& Campbell PG (2005) Osx transcriptional regulation is mediated by additional pathways to BMP2/Smad signaling. J Cell Biochem 95, $518-528$.

64. Ducy P (2000) Cbfa1: a molecular switch in osteoblast biology. Dev Dyn 219, 461-471.

65. Nakashima K, Zhou X, Kunkel G, et al. (2002) The novel zinc finger-containing transcription factor Osterix is required for osteoblast differentiation and bone formation. Cell 108, $17-29$.

66. Lee MH, Kwon TG, Park HS, et al. (2003) BMP-2-induced Osterix expression is mediated by Dlx 5 but is independent of Runx2. Biochem Biophys Res Commun 309, 689-694.

67. Chen CH, Ho ML, Chang JK, et al. (2005) Green tea catechin enhances osteogenesis in a bone marrow mesenchymal stem cell line. Osteoporos Int 16, 2039-2045.

68. Vali B, Rao LG \& El-Sohemy A (2007) Epigallocatechin-3gallate increases the formation of mineralized bone nodules by human osteoblast-like cells. J Nutr Biochem 18, $341-347$

69. De Wilde A, Lieberherr M, Colin C, et al. (2004) A low dose of daidzein acts as an ER $\beta$-selective agonist in trabecular osteoblasts of young female piglets. $J$ Cell Physiol 200, 253-262.

70. Mizutani K, Ikeda K, Kawai Y, et al. (1998) Resveratrol stimulates the proliferation and differentiation of osteoblastic MC3T3-E1 cells. Biochem Biophys Res Commun 253, 859-863.

71. Dai Z, Li Y, Quarles LD, et al. (2007) Resveratrol enhances proliferation and osteoblastic differentiation in human mesenchymal stem cells via ER-dependent ERK1/2 activation. Phytomedicine 14, 806-814.
72. Liu M, Liu HP, Lu XM, et al. (2007) Simultaneous determination of icariin, icariside II and osthole in rat plasma after oral administration of the extract of Gushudan (a Chinese compound formulation) by LC-MS/MS J Chromatogr B 860, 113-120.

73. Zhao J, Ohba S, Shinkai M, et al. (2008) Icariin induces osteogenic differentiation in vitro in a BMP- and Runx2dependent manner. Biochem Biophys Res Commun 369 , 444-448.

74. Pinkus R, Weiner LM \& Daniel V (1996) Role of oxidants and antioxidants in the induction of AP-1, NF- $\mathrm{B}$, and glutathione S-transferase gene expression. J Biol Chem 271, 13422-13429.

75. Fujioka S, Niu JG, Schmidt C, et al. (2004) NF-KB and AP1 connection: mechanism of NF- $\mathrm{KB}$-dependent regulation of AP-1 activity. Mol Cell Biol 24, 7806-7819.

76. Wagner EF (2002) Functions of AP1 (Fos/Jun) in bone development. Ann Rheum Dis 61, Suppl. 2, ii40-ii42.

77. McCabe LR, Kockx M, Lian J, et al. (1995) Selective expression of fos- and jun-related genes during osteoblast proliferation and differentiation. Exp Cell Res 218, 255-262.

78. Frigo DE, Duong BN, Melnik LI, et al. (2002) Flavonoid phytochemicals regulate activator protein-1 signal transduction pathways in endometrial and kidney stable cell lines. J Nutr 132, 1848-1853.

79. Pang JL, Ricupero DA, Huang S, et al. (2006) Differential activity of kaempferol and quercetin in attenuating tumor necrosis factor receptor family signaling in bone cells. Biochem Pharmacol 71, 818-826.

80. Son YO, Kook SH, Choi KC, et al. (2008) Quercetin accelerates TNF- $\alpha$-induced apoptosis of MC3T3-E1 osteoblastic cells through caspase-dependent and JNK-mediated pathways. Eur J Pharmacol 579, 26-33.

81. Lee SU, Shin HK, Min YK, et al. (2008) Emodin accelerates osteoblast differentiation through phosphatidylinositol 3-kinase activation and bone morphogenetic protein-2 gene expression. Int Immunopharmacol 8 , $741-747$.

82. Tokuda H, Takai S, Matsushima-Nishiwaki R, et al. (2007) (-)-Epigallocatechin gallate enhances prostaglandin F2 $\alpha$-induced VEGF synthesis via upregulating SAPK/JNK activation in osteoblasts. $J$ Cell Biochem 100, 1146-1153.

83. Canalis E, Economides AN \& Gazzerro E (2003) Bone morphogenetic proteins, their antagonists, and the skeleton. Endocr Rev 24, 218-235.

84. Yamashita T, Ishii H, Shimoda K, et al. (1996) Subcloning of three osteoblastic cell lines with distinct differentiation phenotypes from the mouse osteoblastic cell line KS-4. Bone 19, 429-436.

85. Miyazono K, Maeda S \& Imamura T (2005) BMP receptor signaling: transcriptional targets, regulation of signals, and signaling cross-talk. Cytokine Growth Factor Rev 16, 251-263.

86. Shi Y \& Massague J (2003) Mechanisms of TGF- $\beta$ signaling from cell membrane to the nucleus. Cell $\mathbf{1 1 3}$ $685-700$.

87. Boden SD, Kang J, Sandhu H, et al. (2002) Use of recombinant human bone morphogenetic protein-2 to achieve posterolateral lumbar spine fusion in humans: a prospective, randomized clinical pilot trial: 2002 Volvo Award in clinical studies. Spine 27, 2662-2673.

88. Zimmerman LB, De Jesús-Escobar JM \& Harland RM (1996) The Spemann organizer signal noggin binds and inactivates bone morphogenetic protein 4. Cell 86, 599-606. 
89. Groppe J, Greenwald J, Wiater E, et al. (2002) Structural basis of BMP signalling inhibition by the cystine knot protein Noggin. Nature 420, 636-642.

90. Gazzerro E, Gangji V \& Canalis E (1998) Bone morphogenetic proteins induce the expression of noggin, which limits their activity in cultured rat osteoblasts. J Clin Invest 102, 2106-2114.

91. Kuo P-L, Hsu Y-L, Chang C-H, et al. (2005) Ostholemediated cell differentiation through bone morphogenetic protein-2/p38 and extracellular signal-regulated kinase $1 / 2$ pathway in human osteoblast cells. J Pharmacol Exp Ther 314, 1290-1299.

92. Tang CH, Yang RS, Chien MY, et al. (2008) Enhancement of bone morphogenetic protein-2 expression and bone formation by coumarin derivatives via p38 and ERKdependent pathway in osteoblasts. Eur J Pharmacol 579, 40-49.

93. Chang JK, Hsu YL, Teng IC, et al. (2006) Piceatannol stimulates osteoblast differentiation that may be mediated by increased bone morphogenetic protein-2 production. Eur J Pharmacol 551, 1-9.

94. Su JL, Yang CY, Zhao M, et al. (2007) Forkhead proteins are critical for bone morphogenetic protein-2 regulation and anti-tumor activity of resveratrol. J Biol Chem 282, 19385-19398.

95. Hsu YL, Chang JK, Tsai CH, et al. (2007) Myricetin induces human osteoblast differentiation through bone morphogenetic protein-2/p38 mitogen-activated protein kinase pathway. Biochem Pharmacol 73, 504-514.

96. Wolter F, Clausnitzer A, Akoglu B, et al. (2002) Piceatannol, a natural analog of resveratrol, inhibits progression through the $\mathrm{S}$ phase of the cell cycle in colorectal cancer cell lines. J Nutr 132, 298-302.

97. Yanez J, Vicente V, Alcaraz M, et al. (2004) Cytotoxicity and antiproliferative activities of several phenolic compounds against three melanocytes cell lines: relationship between structure and activity. Nutr Cancer 49, 191-199.

98. Kousteni S, Bellido T, Plotkin LI, et al. (2001) Nongenotropic, sex-nonspecific signaling through the estrogen or androgen receptors: dissociation from transcriptional activity. Cell 104, 719-730.

99. Kousteni S, Han L, Chen JR, et al. (2003) Kinase-mediated regulation of common transcription factors accounts for the bone-protective effects of sex steroids. J Clin Invest 111, $1651-1664$

100. Manolagas SC, Kousteni S \& Jilka RL (2002) Sex steroids and bone. Recent Prog Horm Res 57, 385-409.

101. Ascenzi P, Bocedi A \& Maria M (2006) Structure-function relationship of estrogen receptor a and b: impact on human health. Mol Aspect Med 27, 299-402.

102. Nilsson S, Makela S, Treuter E, et al. (2001) Mechanisms of estrogen action. Physiol Rev 81, 1535-1565.

103. Losel RM, Falkenstein E, Feuring M, et al. (2003) Nongenomic steroid action: controversies, questions, and answers. Physiol Rev 83, 965-1016.

104. Watson CS, Bulayeva NN, Wozniak AL, et al. (2005) Signaling from the membrane via membrane estrogen receptor- $\alpha$ estrogens, xenoestrogens, and phytoestrogens. Steroids 70, 364-371.

105. Prouillet C, Maziere JC, Maziere C, et al. (2004) Stimulatory effect of naturally occurring flavonols quercetin and kaempferol on alkaline phosphatase activity in MG-63 human osteoblasts through ERK and estrogen receptor pathway. Biochem Pharmacol 67, 1307-1313.

106. Kousteni S, Chen JR, Bellido T, et al. (2002) Reversal of bone loss in mice by nongenotropic signaling of sex steroids. Science 298, 843-846.

107. Dai Z, Li Y, Quarles LD, et al. (2007) Resveratrol enhances proliferation and osteoblastic differentiation in human mesenchymal stem cells via ER-dependent ERK1/2 activation. Phytomedicine 14, 806-814.

108. Weitzmann MN \& Pacifici R (2006) Estrogen deficiency and bone loss: an inflammatory tale. J Clin Invest 116, 1186-1194.

109. Kono SJ, Oshima Y, Hoshi K, et al. (2007) Erk pathways negatively regulate matrix mineralization. Bone 40, 68-74.

110. Driggers PH \& Segars JH (2002) Estrogen action and cytoplasmic signaling pathways. Part II: the role of growth factors and phosphorylation in estrogen signaling. Trends Endocrinol Metab 13, 422-427.

111. Totta P, Acconcia F, Leone S, et al. (2004) Mechanisms of naringenin-induced apoptotic cascade in cancer cells: involvement of estrogen receptor $\alpha$ and $\beta$ signalling. IUBMB Life 56, 491-499.

112. Cassidy A \& Dalais FS (2003) Phytochemicals. In Nutrition and Metabolism, pp. 307-317 [MJ Gibney, IA Macdonald and HM Roche, editors]. Oxford: Blackwell Publishing.

113. Chen XW, Garner SC \& Anderson JJ (2002) Isoflavones regulate interleukin- 6 and osteoprotegerin synthesis during osteoblast cell differentiation via an estrogen-receptordependent pathway. Biochem Biophys Res Commun 295, 417-422.

114. Clifford MN \& Scalbert A (2000) Ellagitannins - nature, occurrence and dietary burden. J Sci Food Agric 80, $1118-1125$

115. Papoutsi Z, Kassi E, Tsiapara A, et al. (2005) Evaluation of estrogenic/antiestrogenic activity of ellagic acid via the estrogen receptor subtypes ER $\alpha$ and ER $\beta$. J Agric Food Chem 53, 7715-7720

116. Simonet WS, Lacey DL, Dunstan CR, et al. (1997) Osteoprotegerin: a novel secreted protein involved in the regulation of bone density. Cell $\mathbf{8 9}, 309-319$.

117. Rodan GA \& Martin TJ (1981) Role of osteoblasts in hormonal control of bone resorption - a hypothesis. Calcif Tissue Int 33, 349-351.

118. Lacey DL, Timms E, Tan HL, et al. (1998) Osteoprotegerin ligand is a cytokine that regulates osteoclast differentiation and activation. Cell 93, 165-176.

119. Yasuda H, Shima N, Nakagawa N, et al. (1998) Osteoclast differentiation factor is a ligand for osteoprotegerin/osteoclastogenesis-inhibitory factor and is identical to TRANCE/RANKL. Proc Natl Acad Sci U S A 95, 3597-3602.

120. Hsu H, Lacey DL, Dunstan CR, et al. (1999) Tumor necrosis factor receptor family member RANK mediates osteoclast differentiation and activation induced by osteoprotegerin ligand. Proc Natl Acad Sci U S A 96, 3540-3545.

121. Bu SY, Hunt TS \& Smith BJ (2009) Dried plum polyphenols attenuate the detrimental effects of TNF- $\alpha$ on osteoblast function coincident with up-regulation of Runx2, Osterix and IGF-I. J Nutr Biochem 20, 35-44.

122. University of Michigan (2005) Bone remodeling. http:// www.umich.edu/news/Releases/2005/Feb05/bone.html 